\title{
Genetic heterogeneity of primary open angle glaucoma and ocular hypertension: linkage to GLC1A associated with an increased risk of severe glaucomatous optic neuropathy
}

Antoine P Brézin, Alain Béchetoille, Pascale Hamard, Françoise Valtot, Merouane Berkani, Ahmed Belmouden, Marie F Adam, Stéphane Dupont de Dinechin, Jean-François Bach, Henri-Jean Garchon

\begin{abstract}
The GLC1A locus for autosomal dominant juvenile and middle age onset primary open angle glaucoma (OAG) has been mapped to chromosome 1q21-q31. OAG, however, is a heterogeneous disease. We tested linkage of OAG and ocular hypertension (OHT), a major risk factor for OAG, to GLC1A in eight French families with multiple cases of juvenile and middle age onset OAG. There was strong evidence of genetic heterogeneity, four families being linked to GLC1A and two or three others being unlinked, depending on whether the complete OAG phenotype was analysed alone or jointly with OHT. Peak intraocular pressure (IOP) did not differ significantly between the two groups of families, while linkage to GLC1A conferred a highly increased risk of developing OAG and of having severe glaucomatous optic neuropathy. Testing linkage of familial OAG to GLC1A may therefore have prognostic value too. (F Med Genet 1997;34:546-552)
\end{abstract}

Keywords: open angle glaucoma; ocular hypertension; genetic heterogeneity; linkage

Glaucoma is the second most common cause of irreversible visual impairment in industrialised countries, with an estimated worldwide prevalence of between 1 and $2 \% .^{1}$ Primary open angle glaucoma (OAG) combines a particular type of damage to the optic disc with a progressive loss of visual field. ${ }^{23}$ Glaucomatous optic atrophy is primarily characterised by an excavated appearance of the disc. This definition of glaucoma, however, encompasses heterogeneous phenotypes. ${ }^{4}$ Ocular hypertension (OHT) is not a diagnostic criterion for glaucoma, but occurs in a large proportion of patients. It is the most consistent risk factor for OAG and can precede the development of glaucomatous optic neuropathy. In animal models, laser induced OHT results in optic disc cupping. ${ }^{5}$ Lowering intraocular pressure (IOP) is currently the best treatment for glaucoma. ${ }^{6}$ Taken together, these observations suggest that, at least in certain forms of glaucoma, raised IOP is a pathogenic mechanism in the development of OAG in humans.
The precise pathogenesis of OHT and OAG is unclear. Epidemiological studies have emphasised the importance of a family history of OAG as a risk factor, strongly suggesting that OAG is influenced by genetic determinants. The juvenile form of OAG (diagnosed before the age of 40 years) is often inherited in a simple mendelian manner, with a highly penetran autosomal mode of transmission. ${ }^{7}$ Clinically, juvenile onset OAG comprises particularly raised IOP (often above $35 \mathrm{~mm} \mathrm{Hg}$ ) resulting in severe optic disc cupping. Linkage analysis of a family affected by juvenile OAG has mapped the disease causing gene to chromosome $1 \mathrm{q} 21-\mathrm{q} 31,{ }^{8}$ currently within a $3 \mathrm{cM}$ interval. ${ }^{111}$

In initial linkage studies, disease onset consistently occurred before the age of $20 .^{9^{12-15}}$ Subsequently, two large families were characterised, in which both juvenile OAG and middle age onset OAG were observed. ${ }^{16}{ }^{17}$ These findings indicated that the range of phenotypes determined by the GLC1A chromosomal region could be broader than initially thought However, GLC1A was also probably excluded in one family with middle age onset $\mathrm{OAG},{ }^{18}$ and a second localisation (GLC1B) on proximal chromosome $2 \mathrm{q}$ was recently proposed. ${ }^{1}$ Therefore, these results raised questions as to the role of the GLC1A locus in middle to late age onset OAG and OHT, which are much more prevalent than juvenile OAG in the general population. To address this essential issue we characterised eight families with two or more cases of OAG associated with OHT. We then assessed linkage of OAG or OHT or both to GLC1A.

\section{Materials and methods}

Information on the possibility of testing linkage to the GLC1A locus in families with five or more members affected by OAG or OHT was communicated to French ophthalmologists Eight consecutive families meeting this requirement and comprising 177 living or dead subjects were included in the study. Informed consent and blood samples were obtained from 137 of the 145 living subjects, in keeping with French legislation.

The complete ophthalmological records of each subject were requested from local ophthalmologists. Clinical assessment included slit Revised version accepted for 1997 
lamp biomicroscopy, applanation tonometry, gonioscopy, and visual field testing, using automated perimeters (Humphrey field analyser, Octopus ${ }^{\mathrm{TM}}$, or Moniteur Ophtalmologique $^{\mathrm{TM}}$ ). Ophthalmological examination was performed by at least one of us $(\mathrm{APB}, \mathrm{AB}$, $\mathrm{PH}, \mathrm{FV}$, or $\mathrm{MB}$ ) on 128 subjects ( $93 \%$ of living subjects). For the purposes of genetic linkage analysis, OAG was diagnosed by the combination of open angle gonioscopy and characteristic cupping of the optic disc with a loss of visual field. Isolated OHT was defined by an IOP $\geqslant 22 \mathrm{~mm} \mathrm{Hg}$ on at least two occasions with a normal appearance of the optic disc and a normal visual field. The IOP threshold of $22 \mathrm{~mm}$ $\mathrm{Hg}$ was retained because it is over two standard deviations above the mean ${ }^{1}$ and it is associated with a dramatic increase in the risk of developing glaucoma. ${ }^{2021}$

Genomic DNA was extracted from purified white blood cells, using established procedures. ${ }^{22}$ Microsatellite markers spanning the GLC1A susceptibility region were chosen from the Généthon linkage map. ${ }^{23}$ The NGA1 tetranucleotide repeat was characterised in our laboratory. ${ }^{11}$ Oligonucleotides were purchased from Genosys ${ }^{\mathrm{TM}}$ with one fluorescently labelled oligonucleotide among each pair of primers (6-FAM for D1S194, D1S196, D1S445, D1S433, D1S452, D1S210, and D1S218, JOE for D1S2851 and NGA1, and TAMRA for D1S242). A fourth dye was used for size standards (ROX 350, Applied Biosystems ${ }^{\mathrm{TM}}$ ). $\mathrm{Up}$ to six amplification products were coprecipitated and comigrated in a $6 \%$ polyacrylamide denaturing gel on an Applied Biosystem 373 Sequencer. The molecular weight of amplified products was calculated by using GENESCAN 1.0 and GENOTYPER 1.0 software.

Pedigree data were exported for linkage analysis with FASTLINK software version 3.0..$^{24}$ Because little is known of the actual frequency of the GLC1A gene in the general population, and also because disease parameters may be critical when testing a model, ${ }^{26}$ four sets of disease parameters were used to test linkage to GLC1A. They were deduced from four values of the proportion of genetic cases (cases caused by the GLC1A locus). These four values $(0.01,0.03,0.1$, and 0.3 ) were estimated from the published figures of OAG prevalence at various ages ${ }^{1}$ and were expected broadly to cover the actual value. A prevalence rate of $1 \%$ in the general population was selected. In all cases, a dominant mode of transmission and a penetrance rate of 0.9 for the disease gene were assumed. The disease gene frequency $P$ was calculated from the frequency of genetically affected subjects (A) using the formula:

$$
A=P^{2} F_{D D}+2 P(1-P) F_{D d}
$$

where $F_{D D}$ and $F_{D d}$ are the penetrance rates of the disease gene in the homozygous and heterozygous state, respectively, whereas the frequency of phenocopies was given by:

$$
\mathrm{C}=(1-\mathrm{P})^{2} \mathrm{~F}_{\mathrm{dd}}
$$

where $F_{d d}$ is the penetrance of the wild type allele. The overall disease frequency (prevalence) is Prev $=\mathrm{A}+\mathrm{C}$. For clarity, only data obtained from $30 \%$ of genetic cases are presented here.

Multipoint analysis was done with the VITESSE algorithm. ${ }^{27}$ Allele frequencies of microsatellite markers were determined in a cohort of 96 spouses from our family set. Family admixture was tested with the HOMOG program. ${ }^{23}$

Clinical features were compared between GLC1A linked and unlinked families by assuming a logistic regression model, taking GLC1A linkage as the dependent variable. Exact estimates of the odds ratios (OR) and their two sided $\mathrm{p}$ values were obtained with LogXact Turbo software. ${ }^{28}$

\section{Results}

CLINICAL FEATURES

We studied 137 living subjects from eight multigeneration families (fig 1). Affected members were found in two to five generations of each family. Of 60 affected patients, 31 were men and 29 were women. Forty-five patients had definite OAG and 15 isolated OHT (table 1). Glaucomatous neuropathy was observed in at least two subjects in each family. There was no evidence of secondary glaucoma, and gonioscopy was normal in all eyes. The age at diagnosis (OHT or OAG) ranged from 7 to 82 years, with a median of 28.5 years (28 years for patients with OAG). A marked rise of IOP was found in some or all affected members of each family, 30 patients having recorded IOP values of $30 \mathrm{~mm} \mathrm{Hg}$ or more in at least one eye. Visual field testing showed an advanced scotoma in at least one eye in 24 patients. Glaucomatous optic atrophy was responsible for a total loss of light perception in 12 eyes. Advanced cupping of the optic disc, with a c/d ratio of 0.9 or more, was observed in 34 eyes. Thirty-four patients had undergone surgery.

Although the clinical features of the probands were similar in all eight families, there seemed to be two subgroups of families with regard to the frequency of isolated OHT, which was not observed in families $A-D$, and of severe glaucomatous optic neuropathy, which seemed to be more frequent in these four families. These differences are analysed further below in the light of linkage data.

LINKAGE ANALYSIS AND GENETIC HETEROGENEITY

Segregation analysis of OHT and OAG indicated that more than $50 \%$ of children of affected parents were affected, and that there was no difference in the rate of paternal versus maternal transmission of disease. There was one obligate carrier in family G. Another carrier (II.2) died at the age of 34, before his clinical status could be documented. A disease model with an autosomal dominant mode of transmission and a penetrance rate of $90 \%$ was therefore adopted to test linkage of OAG/OHT to GLC1A in these eight families. Because the proportion of cases of glaucoma caused by GLC1A, that is, the proportion of genetic cases, is largely unknown, and because its value may markedly alter the significance of the results, four values ( $1 \%$ to $30 \%)$ were 
Table 1 Clinical characteristics of affected family members

\begin{tabular}{|c|c|c|c|c|c|c|c|c|c|}
\hline \multirow[b]{2}{*}{ Patient } & \multirow[b]{2}{*}{ Age } & \multirow[b]{2}{*}{ Diagnosis } & \multirow{2}{*}{$\begin{array}{l}\text { Age at } \\
\text { diagnosis }\end{array}$} & \multirow{2}{*}{$\begin{array}{l}\text { Highest IOP } \\
\text { (either eye) }\end{array}$} & \multicolumn{2}{|c|}{ cld ratio } & \multicolumn{2}{|c|}{ Visual field } & \multirow{2}{*}{$\begin{array}{l}\text { Surgical treatment } \\
\text { (either eye) }\end{array}$} \\
\hline & & & & & $O D$ & os & $O D$ & OS & \\
\hline \multicolumn{10}{|l|}{ Family A } \\
\hline III. 1 & 82 & OAG & 31 & 35 & 1.0 & 1.0 & $\downarrow \downarrow \downarrow \downarrow$ & $\downarrow \downarrow \downarrow \downarrow$ & Yes \\
\hline III. 3 & 75 & OAG & 37 & 35 & 1.0 & 1.0 & $\downarrow \downarrow \downarrow$ & $\downarrow \downarrow \downarrow$ & Yes \\
\hline III. 4 & 73 & OAG & 40 & 40 & 0.9 & 0.9 & $\downarrow \downarrow \downarrow$ & $\downarrow \downarrow \downarrow$ & Yes \\
\hline IV.2 & 51 & OAG & 36 & 34 & $\star$ & $\star$ & $\downarrow \downarrow \downarrow$ & $\downarrow \downarrow \downarrow$ & Yes \\
\hline IV. 6 & 52 & OAG & 30 & 23 & 0.3 & 0.3 & $\downarrow \downarrow \downarrow$ & $\downarrow \downarrow$ & Yes \\
\hline V.1 & 26 & OAG & 22 & 26 & 0.7 & 0.8 & $\downarrow \downarrow$ & $\downarrow \downarrow$ & No \\
\hline V. 2 & 24 & OAG & 20 & 24 & 0.2 & 0.2 & $\downarrow \downarrow$ & $\downarrow \downarrow$ & No \\
\hline Family B & & & & & & & & & \\
\hline I. 1 & 93 & OAG & 20 & NA & 1.0 & 1.0 & $\downarrow \downarrow \downarrow \downarrow$ & $\downarrow \downarrow \downarrow \downarrow$ & No \\
\hline II. 2 & 70 & OAG & 28 & NA & 1.0 & 1.0 & $\downarrow \downarrow \downarrow \downarrow$ & $\downarrow \downarrow \downarrow \downarrow$ & Yes \\
\hline II. 3 & 49 & OAG & 28 & 25 & 0.6 & 0.8 & $\downarrow$ & $\downarrow$ & Yes \\
\hline III. 2 & 45 & OAG & 25 & 40 & 0.8 & 0.9 & $\downarrow \downarrow \downarrow$ & $\downarrow \downarrow \downarrow$ & Yes \\
\hline III. 3 & 36 & OAG & 18 & 35 & 0.9 & 1.0 & $\downarrow \downarrow \downarrow$ & $\downarrow \downarrow \downarrow \downarrow$ & Yes \\
\hline IV.1 & 17 & OAG & 11 & 32 & 0.2 & 0.2 & $\downarrow$ & $\downarrow$ & No \\
\hline IV.2 & 20 & OAG & 18 & 27 & 0.3 & 0.4 & $\downarrow$ & $\downarrow$ & No \\
\hline Family C & & & & & & & & & \\
\hline II. 2 & 71 & OAG & 29 & 37 & 1.0 & 0.9 & $\downarrow \downarrow \downarrow$ & $\downarrow \downarrow \downarrow$ & Yes \\
\hline II. 3 & 73 & OAG & 46 & 28 & 1.0 & 0.9 & $\downarrow \downarrow \downarrow$ & $\downarrow \downarrow \downarrow$ & Yes \\
\hline II. 4 & 74 & OAG & 51 & 48 & NV & NV & $\downarrow \downarrow \downarrow$ & $\downarrow \downarrow \downarrow$ & Yes \\
\hline III. 2 & 47 & OAG & 40 & 35 & 0.9 & 0.9 & $\downarrow \downarrow \downarrow$ & $\downarrow \downarrow \downarrow$ & Yes \\
\hline IV.1 & 24 & OAG & 23 & 40 & 0.5 & 0.6 & $\downarrow \downarrow$ & $\downarrow \downarrow$ & No \\
\hline IV.2 & 22 & OAG & 21 & 28 & 0.9 & 0.9 & $\downarrow \downarrow \downarrow$ & $\downarrow \downarrow$ & Yes \\
\hline Family D & & & & & & & & & \\
\hline III. 2 & 74 & OAG & 27 & NA & 1.0 & 1.0 & $\downarrow \downarrow \downarrow$ & $\downarrow \downarrow \downarrow$ & Yes \\
\hline IV.2 & 44 & OAG & 8 & NA & 0.8 & 0.8 & $\downarrow \downarrow \downarrow$ & $\downarrow \downarrow \downarrow$ & Yes \\
\hline IV.4 & 53 & OAG & 11 & NA & 1.0 & 1.0 & $\downarrow \downarrow \downarrow$ & $\downarrow \downarrow \downarrow \downarrow$ & Yes \\
\hline IV.6 & 49 & OAG & 12 & 40 & 1.0 & 1.0 & $\downarrow \downarrow \downarrow$ & $\downarrow \downarrow \downarrow$ & Yes \\
\hline IV.9 & 48 & OAG & 11 & 45 & 0.8 & 0.6 & $\downarrow \downarrow$ & $\downarrow \downarrow$ & Yes \\
\hline IV.11 & 51 & OAG & 17 & NA & NV & NV & $\downarrow \downarrow$ & $\downarrow$ & Yes \\
\hline V.1 & 9 & OAG & 7 & 36 & 0.7 & 0.7 & $\downarrow \downarrow$ & $\downarrow \downarrow$ & Yes \\
\hline V.4 & 25 & OAG & 8 & 40 & 0.9 & 1.0 & $\downarrow \downarrow \downarrow$ & $\downarrow \downarrow \downarrow$ & Yes \\
\hline V.6 & 25 & OAG & 10 & 35 & 0.4 & 0.3 & NA & NA & Yes \\
\hline V.8 & 28 & OAG & 12 & 40 & 0.7 & 0.7 & $\downarrow \downarrow \downarrow$ & $\downarrow \downarrow$ & Yes \\
\hline Family $\mathrm{E}$ & & & & & & & & & \\
\hline II. 2 & 64 & OAG & 42 & 40 & 0.5 & $t$ & $\downarrow$ & $t$ & Yes \\
\hline II. 3 & 70 & OAG & 40 & 51 & NV & NV & NA & NA & Yes \\
\hline III. 2 & 32 & OAG & 19 & 24 & 0.3 & 0.3 & $\downarrow$ & $\downarrow$ & No \\
\hline III. 3 & 34 & OHT & 16 & 35 & 0.3 & 0.3 & $\mathrm{~N}$ & $\mathrm{~N}$ & No \\
\hline III. 5 & 38 & OHT & 28 & 30 & 0.1 & $0.1 \ddagger$ & $\mathrm{N}$ & $\neq$ & No \\
\hline III.7 & 44 & OAG & 19 & 45 & NV & NV & $\downarrow \downarrow \downarrow$ & $\downarrow \downarrow \downarrow \downarrow$ & Yes \\
\hline III.9 & 53 & OAG & 32 & 45 & 0.6 & 0.2 & $\downarrow \downarrow$ & $\downarrow$ & Yes \\
\hline Family $F$ & & & & & & & & & \\
\hline I. 2 & 87 & OAG & 82 & 58 & 1.0 & 1.0 & $\downarrow \downarrow \downarrow \downarrow$ & $\downarrow \downarrow \downarrow \downarrow$ & Yes \\
\hline II. 2 & 57 & $\mathrm{OHT}$ & 54 & 22 & 0.1 & 0.2 & $\mathrm{~N}$ & $\mathrm{~N}$ & No \\
\hline II. 4 & 46 & $\mathrm{OHT}$ & 43 & 24 & 0.4 & 0.3 & $\mathrm{~N}$ & $\mathrm{~N}$ & No \\
\hline II.6 & 59 & OAG & 56 & 25 & 0.8 & 0.8 & $\downarrow$ & $\downarrow$ & Yes \\
\hline II. 7 & 62 & OAG & 44 & NA & 1.0 & 1.0 & $\downarrow \downarrow \downarrow \downarrow$ & $\downarrow \downarrow \downarrow$ & Yes \\
\hline III. 4 & 21 & $\mathrm{OHT}$ & 19 & 23 & 0.2 & 0.1 & $\mathrm{~N}$ & $\mathrm{~N}$ & No \\
\hline III. 5 & 38 & $\mathrm{OHT}$ & 33 & 28 & 0.4 & 0.3 & $\mathbf{N}$ & $\mathrm{N}$ & No \\
\hline III.7 & 35 & OHT & 32 & 27 & 0.5 & 0.4 & $\mathbf{N}$ & $\mathrm{N}$ & No \\
\hline III. 8 & 34 & $\mathrm{OHT}$ & 32 & 22 & 0.3 & 0.3 & $\mathrm{~N}$ & $\mathbf{N}$ & No \\
\hline III.9 & 33 & OAG & 31 & 28 & 0.8 & 0.8 & $\downarrow$ & $\downarrow$ & No \\
\hline III. 10 & 32 & OHT & 30 & 24 & 0.8 & 0.7 & $\mathrm{~N}$ & $\mathrm{~N}$ & No \\
\hline III.11 & 31 & OHT & 25 & 22 & 0.2 & 0.3 & $\mathrm{~N}$ & $\mathbf{N}$ & No \\
\hline Family G & & & & & & & & & \\
\hline IV. 2 & 65 & OAG & 60 & 38 & 0.4 & 0.3 & $\mathrm{~N}$ & $\downarrow$ & No \\
\hline IV. 3 & 63 & OAG & 58 & 25 & 0.5 & 0.6 & $\downarrow$ & $\downarrow$ & No \\
\hline IV. 5 & 51 & OAG & 47 & 32 & 0.6 & NV & $\downarrow$ & $\downarrow$ & Yes \\
\hline IV.8 & 51 & OHT & 34 & 24 & 0.2 & 0.2 & $\mathrm{~N}$ & $\mathrm{~N}$ & No \\
\hline IV.10 & 59 & OHT & 50 & 28 & 0.5 & 0.6 & $\mathrm{~N}$ & $\mathrm{~N}$ & No \\
\hline V.1 & 41 & OAG & 36 & 34 & 0.9 & 0.8 & $\downarrow \downarrow \downarrow$ & $\downarrow \downarrow$ & Yes \\
\hline Family $\mathrm{H}$ & & & & & & & & & \\
\hline II. 2 & 39 & OAG & 38 & 37 & 0.5 & 0.6 & $\mathbf{N}$ & $\downarrow$ & Yes \\
\hline II. 3 & 34 & OAG & 34 & 36 & 0.5 & 0.4 & $\downarrow$ & $\downarrow$ & No \\
\hline III. 1 & 18 & OHT & 17 & 27 & 0.2 & 0.2 & $\mathrm{~N}$ & $\mathrm{~N}$ & No \\
\hline III. 5 & 17 & OHT & 16 & 33 & 0.3 & 0.3 & $\mathrm{~N}$ & $\mathrm{~N}$ & No \\
\hline III. 6 & 14 & OHT & 13 & 28 & 0.2 & 0.3 & $\mathbf{N}$ & $\mathrm{N}$ & No \\
\hline
\end{tabular}

IOP is in mm Hg. NA: not available, NV: not visualised. ${ }^{\star}$ Tilted disc syndrome. $†$ Trauma. $¥$ Unilateral myopia. Visual field: $\mathrm{N}=$ normal, $\downarrow=$ early defect, $\downarrow \downarrow=$ arcuate scoroma or nasal step, $\downarrow \downarrow \downarrow=$ advanced scotoma, $\downarrow \downarrow \downarrow \downarrow=$ no light perception.

considered on the basis of epidemiological data (see Materials and methods). Pairwise lod score data obtained with an assumed proportion of genetic cases of $30 \%$ are shown for five of the eight markers tested in table 2 (data not shown for D1S210, D1S452, and D1S242). Four families (A-D) had a positive lod score with two or more markers. Family D had a lod score above 3 with five of the eight markers tested across the susceptibility region. Conversely, three other families $(\mathrm{E}, \mathrm{F}, \mathrm{H})$ had a lod score $<-2$ with three or more markers, suggesting an absence of linkage. When the proportion of genetic cases was reduced, positive lod scores (families A-D) hardly varied, whereas negative lod scores fell by one unit or more, therefore increasing evidence against linkage (data not shown).

To test further the heterogeneity of linkage, four point analysis was carried out across two successive and overlapping subsets of markers (D1S194-D1S445-D1S2851 and D1S445D1S2851-D1S218) encompassing the GLC1A interval. Testing family admixture with the 

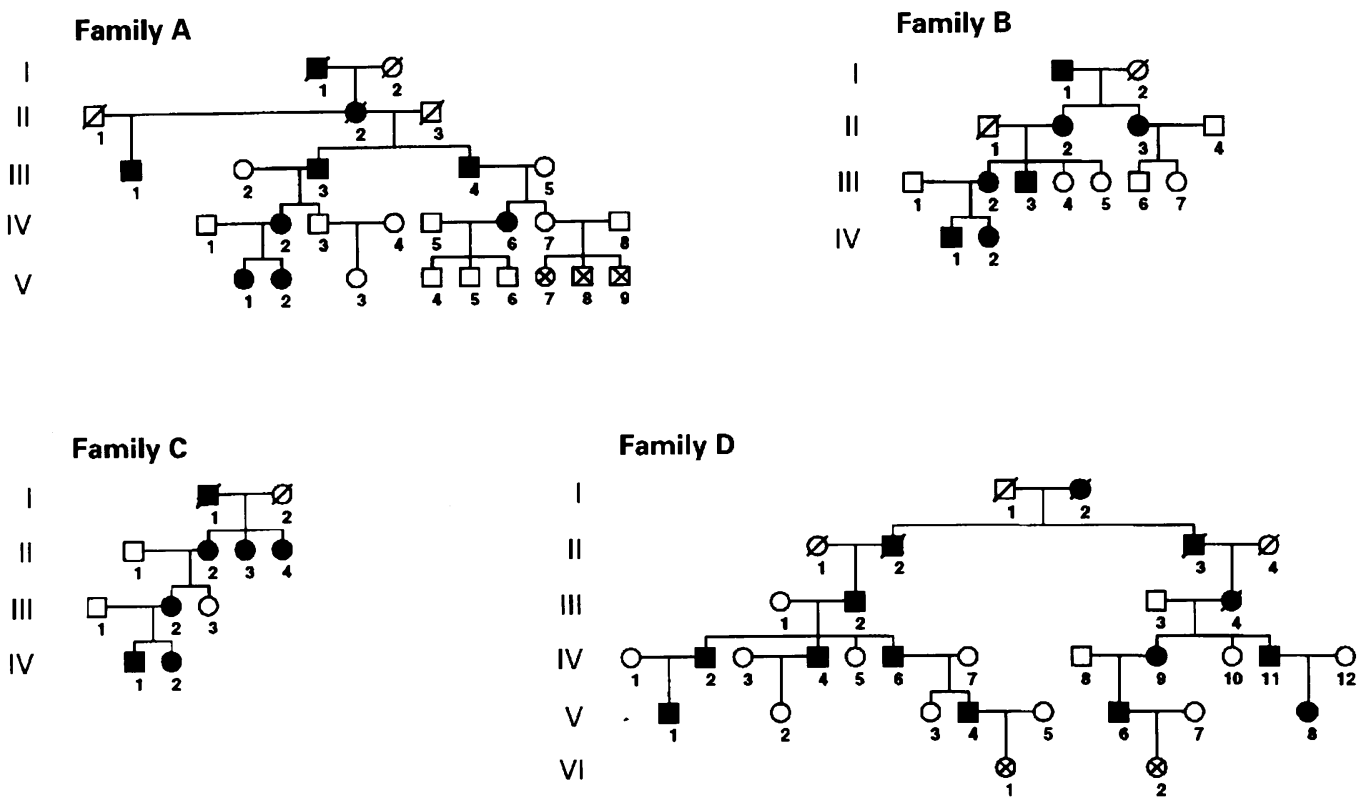

Family E

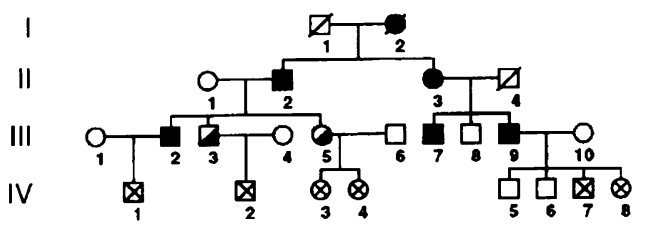

Family $F$

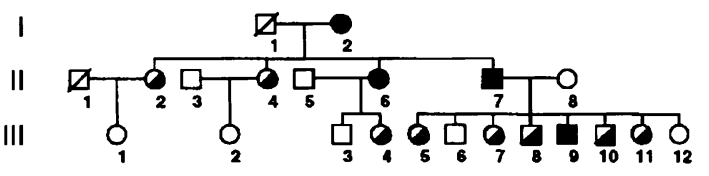

Family G

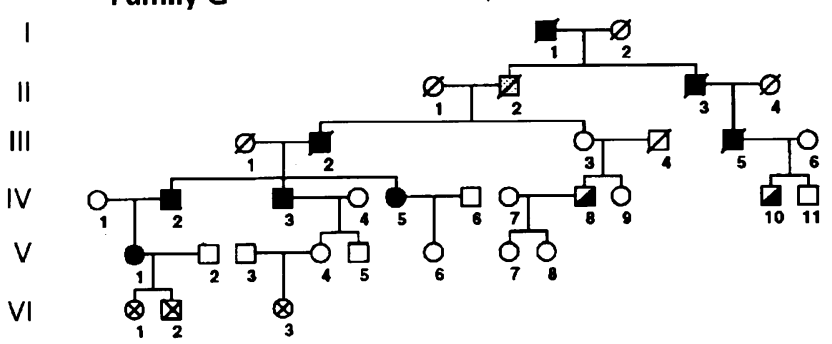

Family $\mathbf{H}$

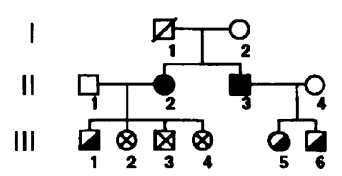

Figure 1 Pedigree of families with $O A G$ or OHT. Filled symbols indicate subjects with $O A G$ and half filled symbols indicate subjects with OHT only. Crossed symbols designate unaffected subjects under 18 years of age (their disease status is unknown). Among living subjects, only those who could be contacted for the study are included in the figure.

HOMOG program strongly supported the hypothesis of linkage and heterogeneity versus the hypothesis of linkage and no heterogeneity. The $\chi^{2}$ value varied between 30.986 and $30.215\left(\mathrm{p}<10^{-4}\right)$ when the proportion of genetic cases was varied between 0.01 and 0.3 . The proportion of families with linkage varied between 0.51 and 0.54 (95\% confidence interval 0.13-0.90).

Families A-D had a posterior probability of being linked to GLC1A exceeding 0.96. Families $\mathrm{E}$ and $\mathrm{F}$ had a posterior probability of being linked below 0.005 . Fig $2 \mathrm{~A}$ shows the individual multipoint (five point) curves for these two families. Multipoint lod scores remained $<-2$ from D1S194 to D1S218, therefore largely covering the GLC1A region, which is currently bound by the NGA1 and NGA5 markers, within the D1S2851-D1S218 interval. ${ }^{11}$ No conclusion could be drawn in the case of family $\mathrm{G}$ (posterior probability of being linked $0.25,95 \%$ confidence interval $0.04-$ 0.71 ). As for family $\mathrm{H}$, the D1S445 marker not being informative in this pedigree, two additional markers closely linked to D1S445, D1S196 and D1S433, were typed in this family and six point analysis was conducted with the D1S194-D1S196-D1S433-D1S2851-D1S218 grid of markers. This analysis clearly excluded linkage of the OAG/OHT to GLC1A in pedigree $\mathrm{H}$ (fig $2 \mathrm{~B}$ ), with lod scores $<-2$ from D1S196 to and beyond D1S218.

Because OHT is not a perfect predictor of OAG, linkage analysis including only subjects affected with OAG was repeated in families E-H. Despite a smaller number of informative meioses, linkage of OAG alone to GLC1A was excluded by a four point analysis in families $\mathrm{E}$ 
Table 2 Two point lod scores for OAG/OHT and GLC1A locus microsatellite markers in eight families

\begin{tabular}{|c|c|c|c|c|c|c|c|}
\hline \multirow[b]{2}{*}{ Markers } & \multicolumn{5}{|l|}{$\theta$} & \multirow[b]{2}{*}{$Z \max$} & \multirow[b]{2}{*}{$\theta(\%)$} \\
\hline & 0.0 & 0.01 & 0.05 & 0.1 & 0.2 & & \\
\hline \multicolumn{8}{|l|}{ D1S194 } \\
\hline A & -0.21 & 0.12 & 0.51 & 0.62 & 0.58 & 0.63 & 0.126 \\
\hline B & 1.62 & 1.60 & 1.49 & 1.36 & 1.07 & 1.62 & 0.001 \\
\hline C & 0.52 & 0.50 & 0.44 & 0.36 & 0.21 & 0.52 & 0.001 \\
\hline D & 1.17 & 1.14 & 1.02 & 0.87 & 0.59 & 1.17 & 0.001 \\
\hline $\mathrm{E}$ & -2.24 & -1.08 & -0.46 & -0.22 & -0.04 & & $>0.5$ \\
\hline $\mathrm{F}$ & -1.55 & -0.32 & -0.86 & -0.58 & -0.27 & & $>0.5$ \\
\hline G & 0.38 & 0.45 & 0.57 & 0.59 & 0.46 & 0.59 & 0.082 \\
\hline $\mathrm{H}$ & -0.57 & -0.24 & 0.18 & 0.33 & 0.38 & 0.38 & 0.173 \\
\hline \multicolumn{8}{|l|}{ D1S445 } \\
\hline A & 0.23 & 0.26 & 0.35 & 0.37 & 0.33 & 0.37 & 0.105 \\
\hline B & 0.59 & 0.58 & 0.53 & 0.46 & 0.33 & 0.59 & 0.001 \\
\hline $\mathrm{C}$ & -0.16 & -0.15 & -0.12 & -0.09 & -0.05 & & $>0.5$ \\
\hline $\mathrm{D}$ & 0.46 & 0.91 & 1.29 & 1.33 & 1.11 & 1.33 & 0.085 \\
\hline $\mathrm{E}$ & -0.95 & -0.71 & -0.33 & -0.14 & -0.01 & & $>0.5$ \\
\hline $\mathrm{F}$ & -2.91 & -2.80 & -2.12 & -1.45 & -0.58 & 0.05 & 0.428 \\
\hline G & -1.20 & -1.10 & -0.63 & -0.27 & 0.03 & 0.96 & 0.301 \\
\hline $\mathrm{H}$ & 0.10 & 0.10 & 0.09 & 0.07 & 0.04 & 0.10 & 0.001 \\
\hline \multicolumn{8}{|c|}{ D1S2851 } \\
\hline A & 1.46 & 1.48 & 1.51 & 1.45 & 1.18 & 1.51 & 0.041 \\
\hline B & 1.41 & 1.39 & 1.28 & 1.15 & 0.88 & 1.41 & 0.001 \\
\hline C & 1.31 & 0.29 & 1.17 & 1.02 & 0.72 & 1.31 & 0.001 \\
\hline D & 3.92 & 3.85 & 3.58 & 3.22 & 2.46 & 3.92 & 0.001 \\
\hline $\mathrm{E}$ & -1.77 & -0.55 & 0.05 & 0.23 & 0.29 & 0.30 & 0.182 \\
\hline $\mathrm{F}$ & -1.74 & -1.14 & -0.25 & 0.14 & 0.41 & 0.43 & 0.248 \\
\hline G & -1.72 & -1.44 & -1.07 & -0.89 & -0.60 & & $>0.5$ \\
\hline $\mathrm{H}$ & -3.10 & -1.52 & -0.43 & 0.00 & 0.30 & 0.34 & 0.265 \\
\hline \multicolumn{8}{|l|}{ NGA1 } \\
\hline A & 0.49 & 0.60 & 0.78 & 0.82 & 0.69 & 0.82 & 0.090 \\
\hline B & 2.01 & 1.97 & 1.83 & 1.66 & 1.28 & 2.01 & 0.001 \\
\hline C & 1.24 & 1.21 & 1.10 & 0.96 & 0.67 & 1.24 & 0.001 \\
\hline D & 3.37 & 3.30 & 3.04 & 2.71 & 2.03 & 3.37 & 0.001 \\
\hline $\mathrm{E}$ & -3.45 & -2.10 & -0.98 & -0.48 & -0.08 & & $>0.5$ \\
\hline $\mathrm{F}$ & -2.28 & -2.27 & -2.06 & -1.56 & -0.77 & & $>0.5$ \\
\hline G & -1.23 & -1.06 & -0.64 & -0.38 & -0.16 & & $>0.5$ \\
\hline $\mathrm{H}$ & -3.34 & -1.77 & -0.67 & -0.21 & 0.13 & 0.21 & 0.301 \\
\hline \multicolumn{8}{|l|}{ D1S218 } \\
\hline A & 0.75 & 0.82 & 0.96 & 1.02 & 0.92 & 1.02 & 0.103 \\
\hline B & 0.71 & 0.73 & 0.76 & 0.77 & 0.69 & 0.77 & 0.075 \\
\hline C & 1.32 & 1.29 & 1.17 & 1.03 & 0.73 & 1.32 & 0.001 \\
\hline $\mathrm{D}$ & 2.16 & 2.12 & 1.94 & 1.71 & 1.25 & 2.16 & 0.001 \\
\hline $\mathrm{E}$ & -3.09 & -1.75 & -0.89 & -0.48 & -0.12 & & $>0.5$ \\
\hline $\mathrm{F}$ & -5.51 & -3.91 & -1.81 & -0.83 & -0.03 & 0.24 & 0.340 \\
\hline G & -0.92 & -0.64 & -0.28 & -0.14 & 0.02 & & $>0.5$ \\
\hline $\mathrm{H}$ & -3.12 & -1.52 & -0.43 & 0.00 & 0.30 & 0.34 & 0.264 \\
\hline
\end{tabular}

and $F$, throughout the D1S2851-D1S218 interval (fig 2C). No conclusion could be drawn for families $\mathrm{G}$ and $\mathrm{H}$ (not shown).

Altogether linkage analysis provided strong evidence of genetic heterogeneity. Linkage to GLC1A was supported in four families (A-D) and was excluded in two or three other families (E, F or E, F, H), depending on whether the complete OAG phenotype was analysed alone or jointly with OHT.

Table 3 Comparison of phenotypes in GLC1A linked and GLC1A unlinked families

\begin{tabular}{lll}
\hline & $\begin{array}{l}\text { Odds ratio (95\% } \\
\text { confidence interval) }\end{array}$ & p value \\
\hline Exclusion based on OAG and OHT cases & & \\
Age at diagnosis & $0.95(0.90-0.99)$ & 0.011 \\
Age at diagnosis, excluding family D & $0.97(0.93-1.02)$ & $\mathrm{NS}$ \\
Peak IOP & $1.04(0.99-1.09)$ & $\mathrm{NS}$ \\
Cup/disc ratio & $49.9(5.36-634)$ & 0.0002 \\
Advanced scotoma in at least one eye & $3.35(1.88-6.38)$ & $<10^{-4}$ \\
Filtration surgery in at least one eye & $7.64(2.03-33)$ & 0.0013 \\
Isolated OHT & $44.2(6.58-\infty)$ & $<10^{-4}$ \\
Exclusion based on OAG cases only & & \\
Age at diagnosis & $0.93(0.88-0.98)$ & 0.003 \\
Age at diagnosis, excluding family D & $0.96(0.90-1.01)$ & $\mathrm{NS}$ \\
Peak IOP & $1.03(0.99-1.09)$ & $\mathrm{NS}$ \\
Cup/disc ratio & $30.3(3.13-390)$ & 0.002 \\
Advanced scotoma in at least one eye & $2.97(1.66-6.10)$ & $<10^{-4}$ \\
Filtration surgery in at least one eye & $6.54(1.6-30.6)$ & 0.006 \\
Isolated OHT & $40.3(5.7-\infty)$ & $<10^{-4}$ \\
\hline
\end{tabular}

NS $=$ not significant.
GENETIC HETEROGENEITY CORRELATES WITH PHENOTYPIC HETEROGENEITY

A logistic regression model was used to compare phenotypes in GLC1A linked (A-D) and unlinked families. This comparison lent strong statistical support to the feeling that two subgroups of families could be identified on the basis of disease frequency and severity in each family. Whether linkage was excluded on the basis of both OAG and OHT or OAG alone, similar conclusions could be reached (table 3 ). Linkage to GLC1A conferred a highly increased risk of glaucoma as opposed to isolated OHT (odds ratio, $\mathrm{OR}=44.2, \mathrm{p}<10^{-4} ; \mathrm{OR}=40.3$, $\mathrm{p}<10^{-4}$, respectively), and of severe glaucomatous optic neuropathy, as judged by optic disc cupping $(\mathrm{OR}=49.9, \mathrm{p}=0.0002 ; \quad \mathrm{OR}=30.3$, $p=0.002)$, severe impairment of visual field $\left(\mathrm{OR}=3.35, \mathrm{p}<10^{-4} ; \mathrm{OR}=2.97, \mathrm{p}<10^{-4}\right)$, and indications for surgery $(O R=7.64, p=0.0013$; $\mathrm{OR}=6.54, \mathrm{p}=0.006)$. In striking contrast, peak IOP was not different between the two sets of families, even after adjusting for confounding factors such as family size and age at the time of diagnosis.

Age at the time of diagnosis was mildly influenced by linkage to GLC1A and was slightly younger in GLC1A linked than in GLC1A unlinked families $(\mathrm{OR}=0.95$, 

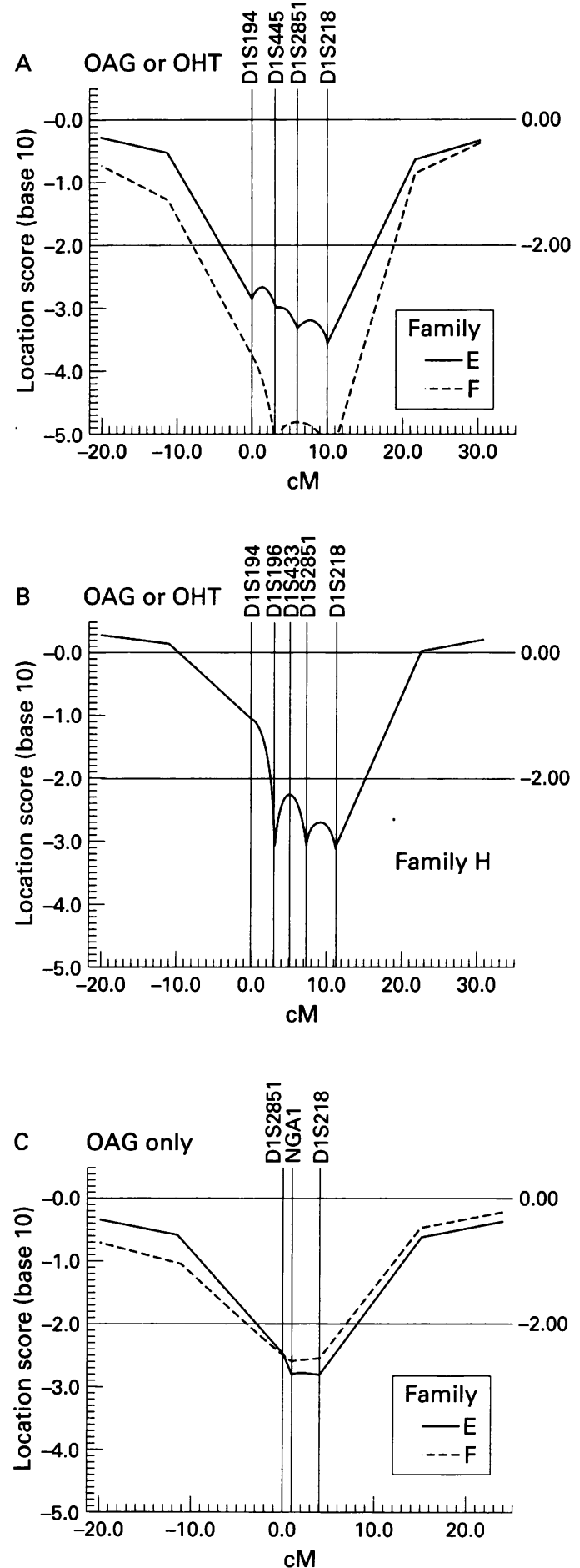

Figure 2 Multipoint analysis of $O A G / O H T(A, B)$ or $O A G$ only $(C)$ for families $E, F(A, C)$, and $H(B)$. The grid of test markers is indicated above each plot. Distances ( $x$ axis) are in cM. They were drawn from the Généthon linkage map ${ }^{23}$ or were deduced from the physical map of the GLC1A region, in which $1 \mathrm{cM}$ is approximately equivalent to $1 \mathrm{Mb} .{ }^{\text {" }}$ Four sets of disease parameters were used (see Materials and methods). Only results corresponding to a proportion of 0.3 genetic cases are shown. Other proportions tested $(0.1,0.03$, and 0.01$)$ yielded smaller multipoint lod scores, therefore increasing evidence against linkage in these families.

$\mathrm{p}=0.011 ; \mathrm{OR}=0.93, \mathrm{p}=0.003)$. However, the group of GLC1A linked families by itself was heterogeneous regarding this criterion, as age at the time of diagnosis was significantly younger in family $\mathrm{D}$ than in the other three GLC1A linked families (OR $=1.31,95 \%$ confidence interval $\left.=1.11-1.66, \mathrm{p}<10^{-4}\right)$. The differ- ence between the two sets of families disappeared after removal of family $D$.

\section{Discussion}

Raised IOP, as a main risk factor for OAG, is likely to play a major role in its pathophysiology. Taking OHT into consideration was therefore legitimate and usefully increased the number of informative meioses, notably in families E-H. Indeed, the segregation pattern of OHT/OAG in these families was compatible with autosomal dominant inheritance and high penetrance. In this context, joint linkage analysis of OAG and OHT showed heterogeneity with regard to linkage to GLC1A. Linkage in the specified model and using a broad range of disease parameters was unambiguously ruled out in three families, whereas no conclusion could be drawn regarding a fourth family. However, because the relationship between $\mathrm{OHT}$ and OAG is not unequivocal, it was critical also to restrict our analysis to OAG only cases. Importantly, in two of the three unlinked families, linkage to GLC1A remained excluded.

An unknown number of genes not located on chromosome 1q may play a role in these GLC1A unlinked families. Other loci for rare forms of glaucoma, including glaucoma associated with iris hypoplasia ${ }^{29}$ and congenital glaucoma, ${ }^{30}$ were recently mapped to chromosomes $4 \mathrm{q}$ and $2 \mathrm{p}$, respectively. These regions are unlikely candidates for linkage with OAG and $\mathrm{OHT}$ in our GLC1A unlinked families, as their clinical features differ markedly from those of both recently mapped forms of glaucoma. More relevant to our discussion is the recent localisation of a second locus for OAG, GLC1B, on chromosome 2qcen-q13. ${ }^{19}$ However, none of our families (E-H) appeared to be linked to GLC1B, whether OAG only or OAG/OHT cases were included in the linkage analysis (MFA and HJG, unpublished data), suggesting the existence of at least a third disease locus.

The most remarkable finding in this study resulted from the comparison of clinical features in GLC1A linked and unlinked families. Linkage to GLC1A appeared to be a major risk factor for the development of glaucoma and severe glaucomatous optic neuropathy, as judged by various criteria including optic disc cupping, severe alteration of the visual field, and the decision to undertake surgical treatment, whereas it did not influence the magnitude of the increase in IOP. In the previously reported GLC1A unlinked family, severity of disease varied greatly. Therefore, lack of linkage to GLC1A would predict a better prognosis. In a recent 12 year follow up study of persons with OHT and an initially normal visual field by Quigley et al, ${ }^{31}$ surprisingly, a family history of glaucoma was not a significant risk factor for OAG in a subject with isolated OHT. Risk factors identified in this work and relevant to our findings included older age, higher IOP, characteristic modifications of the optic disc, and alterations of the nerve fibre layer at the initial visit. The latter two risk factors are in fact early signs of optic 
nerve damage. It would be most interesting to test whether a family history of glaucoma with GLC1A linkage is also a significant risk factor for developing glaucoma in such a cohort of subjects with isolated OHT. Our results should also have a significant role for optimising the management of members of glaucoma families, as raised IOP is probably a reliable parameter of disease evolution in GLC1A linked families, whereas it may be less valuable in GLC1A unlinked families.

We are most grateful to Ms Lucienne Gomez for exper secretarial assistance, $M$ Bruno Copin for technical help, D Elise Héon for critical reading of the manuscript, Dr Garrigues Dr Dhédin, and Dr Billet for allowing us to contact families an for giving us access to their records, and the families for their cooperation. This work was supported by funds from INSERM, coperation Association GREG-genome (grant 20/94), and Association Française de Lutte contre les Myopathies.
pour la Recherche Médicale.

1 Leske MC. The epidemiology of open-angle glaucoma: review. Am $\mathcal{F}$ Epidemiol 1983;118:166-91.

2 ruigley HA Medical progress - open-angle glaucoma. $N$ Engl f Med 1993;328:1097-106.

3 Kaufman PL, Mittag TW. Glaucoma. London: Mosby,

1994.

4 Khan HA, Milton RC. Alternative definitions of open-angle glaucoma. Effect on prevalence and associations in the Framingham eye study. Arch Ophthalmol 1980;98:2172-7.

5 Gaasterland D, Kupfer C. Experimental glaucoma in th rhesus monkey. Invest Ophthalmol Vis $S c i$ 1974;13:455-7.

6 Kass MA, Gordon MO, Hoff MR, et al. Topical Timolo administration reduces the incidence of glaucomatous damage in ocular hypertensive individuals. A randomized, double-masked, long-term clinical trial. Arch Ophthalmo 1989;107:1590-8.

7 François J. Genetics and primary open-angle glaucoma. $\mathrm{Am}$ f Ophthalmol 1966;61:652-65.

8 Johnson AT, Drack AV, Kwitek AE, et al. Clinical features and linkage analysis of a family with autosomal dominan and linkage analysis of a family with autosomal domile glaucoma. Ophthalmology 1993;100:524-9.

9 Sheffield VC, Stone EM, Alward WLM, et al. Genetic linkage of familial open angle glaucoma to chromosome 1q21 q31. Nat Genet 1993;4:47-50.

10 Sunden SLF, Alward WLM, Nichols BE, et al. Fin mapping of the autosomal dominant juvenile open-angl glaucoma (GLC1A) region and evaluation of candidate genes. Genome Res 1996;6:862-9.

11 Belmouden A, Adam MF, Dupont de Dinechin S, et al. Recombinational and physical mapping of the locus for primary open-angle glaucoma (GLC1A) on chromosome 1q23-q25. Genomics 1997;39:348-58.

12 Richards JE, Lichter PR, Boehnke M, et al. Mapping of a gene for autosomal dominant juvenile-onset open-angle glaucoma to chromosome 1q. Am $\mathcal{f}$ Hum Genet 1994;54: 62-70.
13 Wiggs JL, Haines JL, Paglinauan C, et al. Genetic linkage of autosomal dominant juvenile glaucoma to $1 \mathrm{q} 21-\mathrm{q} 31$ in three affected pedigrees. Genomics 1994;21:299-303.

14 Graff C, Urbak SF, Jerndal T, et al. Confirmation of linkage to 1q21-31 in a Danish autosomal dominant juvenile-onset glaucoma family and evidence of genetic heterogeneity. Hum Genet 1995;96:285-9.

15 Johnson AT, Richards JE, Boehnke M, et al. Clinical phenotype of juvenile-onset primary open-angle glaucoma linked to chromosome 1q. Ophthalmology 1996;103:808-14.

16 Morissette J, Coté G, Anctil JL, et al. A common gene for juvenile and adult-onset primary open-angle glaucomas confined on chromosome 1q. Am F Hum Genet 1995;56: 1431-42.

17 Meyer A, Béchetoille A, Valtot F, et al. Age-dependent penetrance and mapping of the locus for juvenile and early-onset open-angle glaucoma on chromosome 19 early-onset open-angle glaucoma on chromosome 1q

18 Richards JE, Lichter PR, Herman S, et al. Probable exclusion of GLC1A as a candidate glaucoma gene in a family with middle-age onset primary open-angle glaucoma. Ophthalmology 1996;103:1035-40.

19 Stoilova D, Child A, Trifan OC, et al. Localization of a locus (GLC1B) for adult-onset primary open-angle glaucoma to the 2qcen-q13 region. Genomics 1996;36:142-50.

20 Armaly MF, Krueger DE, Maunder L et al. Biostatistical analysis of the collaborative glaucoma study. I. Summary report of the risk factors for glaucomatous visual-field report of the risk factors for glaucomato
defects. Arch Ophthalmol 1980;98:2163-71.

21 Sommer A, Tielsch JM, Katz J, et al. Relationship between intraocular pressure and primary open angle glaucoma among White and Black Americans. The Baltimore Eye Survey. Arch Ophthalmol 1991;109:1090-5.

22 Sambrook J, Fritsch EF, Maniatis T. Molecular cloning : a laboratory manual. 2nd ed. New York: Cold Spring Harbor Laboratory Press, 1989.

23 Dib C, Faure S, Fizames C, et al. A comprehensive genetic map of the human genome based on 5,264 microsatellites. Nature 1996;380:152-4.

24 Lathrop GM, Lalouel JM. Easy calculations of lod scores and genetic risks on small computers. Am 7 Hum Genet 1984;36:460-5

25 Cottingham RW, Idury RM, Schaffer AA. Faster sequential genetic linkage computations. Am f Hum Genet 1993;53: $252-63$.

26 Ott J. Analysis of human genetic linkage. Revised edition. Baltimore: Johns Hopkins University Press, 1991.

27 O'Connell JR, Weeks DE. The VITESSE algorithm for rapid exact multilocus linkage analysis via genotype set-recoding and fuzzy inheritance. Nat Genet 1995;11: 402-8.

28 Mehta C, Patel N. LogXact-Turbo. User manual. Cambridge, MA: Cytel Software Corporation, 1993.

29 Héon E, Sheth BP, Kalenak JW, et al. Linkage of autosomal dominant iris hypoplasia to the region of the Rieger syndrome locus (4q25). Hum Mol Genet 1995;4:1435-9.

30 Sarfarazi M, Akarsu AN, Hossain A, et al. Assignment of a locus (GLC3A) for primary congenital glaucoma (buphthalmos) to $2 \mathrm{p} 21$ and evidence for genetic heterogeneity. Genomics 1995;30:171-7.

31 Quigley HA, Enger C, Katz J, et al. Risk factors for the development of glaucomatous visual field loss in ocular hypertension. Arch Ophthalmol 1994;112:644-9. 